\title{
El Caso “Marbury Vs. Madison" en la enseñanza del Derecho Constitucional en Bolivia
}

\author{
The "Marbury Vs. Madison" Case in the teaching of Constitutional Law in Bolivia \\ O Caso "Marbury Vs. Madison" no ensino de Direito Constitucional na Bolívia
}

Artículo recibido en enero 2021

Arbitraje en febrero 2021

Aceptación en marzo 2021

Publicación en abril 2021
Alan E. Vargas Lima

alanvargas4784@gmail.com https://orcid.org/0000-0001-6372-7870

RESUMEN

\section{ABSTRACT}

\section{RESUMO}

El pasado 24 de febrero, se ha cumplido un aniversario más del nacimiento del sistema de control jurisdiccional difuso de constitucionalidad; y hago propicia esta oportunidad para poder repasar algunos rasgos esenciales sobre sus orígenes y su naturaleza jurídica, poniendo de relieve algunas de las características más importantes que lo distinguen de otros sistemas de control, para luego hacer énfasis acerca de su vigencia poco efectiva en Bolivia, lo que ciertamente contrasta con su enorme influencia y utilidad para la enseñanza del Derecho Constitucional.

Palabras clave: Control de constitucionalidad; Control jurisdiccional difuso; Derecho constitucional; Derecho procesal constitucional; Marbury vs. Madison

On February 24, one more anniversary of the birth of the fuzzy jurisdictional control system of constitutionality has been completed; and I take this opportunity to review some essential features about its origins and its legal nature, highlighting some of the most important characteristics that distinguish it from other control systems, and then emphasize its ineffective validity in Bolivia, which certainly contrasts with its enormous influence and usefulness for the teaching of Constitutional Law.

Key words: Control of constitutionality; Fuzzy jurisdictional control; Constitutional right; Constitutional procedural law; Marbury vs. Madison

Em 24 de fevereiro, completou-se mais um aniversário do nascimento do sistema fuzzy de controle jurisdicional de constitucionalidade; e aproveito para revisar algumas características essenciais sobre suas origens e sua natureza jurídica, destacando algumas das características mais importantes que o distinguem de outros sistemas de controle e, em seguida, enfatizar sua validade ineficaz na Bolívia, o que certamente contrasta com sua enorme influência e utilidade para o ensino do Direito Constitucional.

Palavras-chave: Controle de constitucionalidade; Controle jurisdicional difuso; Direito constitucional; Direito processual constitucional; Marbury vs. Madison 
De acuerdo a la doctrina del Derecho Procesal Constitucional en Bolivia, y desde el punto de vista del órgano encargado de realizar el control, se pueden identificar dos sistemas de control de constitucionalidad: el sistema de control político de constitucionalidad y el sistema de control jurisdiccional de constitucionalidad.

En el sistema de control jurisdiccional de constitucionalidad ${ }^{1}$, la doctrina reconoce a su vez dos sistemas o modelos, que se denominan: a) sistema de control jurisdiccional difuso (modelo norteamericano o de la judicial review of legislation), y; b) sistema de control jurisdiccional concentrado (modelo europeo-kelseniano) ${ }^{2}$.

En esta ocasión y en atención a la delimitación del tema planteado, resulta conveniente realizar un breve resumen de los rasgos esenciales más distintivos del sistema de control jurisdiccional "difuso" de constitucionalidad, para luego incidir en su enorme utilidad para la enseñanza del Derecho Constitucional en Bolivia.

MÉTODO

En el proceso de investigación, se utilizó el método histórico-descriptivo, partiendo de los antecedentes históricos del sistema de control jurisdiccional difuso de constitucionalidad, el contexto de surgimiento del caso Marbury vs. Madison en Norteamérica, para luego proyectar la influencia de sus principales características en el sistema de control de constitucionalidad que se ha implementado en Bolivia.

\section{RESULTADOS Y DISCUSIÓN}

Se destaca la enorme influencia que ha tenido el caso Marbury vs. Madison en la enseñanza del Derecho Constitucional en Bolivia, dado que su utilidad radica en que muestra claramente la evolución que han tenido los sistemas de control de constitucionalidad, como mecanismos idóneos para lograr la efectividad de los mandatos establecidos por la Constitución.

\footnotetext{
$1 \quad$ A tiempo de analizar el control jurisdiccional de constitucionalidad de las leyes, diferenciando los modelos clásicos de control, el profesor Duverger señalaba: "Para que el control de la constitucionalidad de las leyes asegure la protección de las libertades, es preciso que los ciudadanos puedan ponerlo también en marcha. Esto conduce a un control jurisdiccional, es decir, a un control ejercido por un órgano que tenga la cualidad de tribunal. Se pueden aplicar, entonces, dos sistemas. O bien los ciudadanos (y los órganos gubernamentales) pueden recurrir ante un tribunal especial, exclusivamente encargado de controlar la constitucionalidad de las leyes: es el sistema alemán e italiano del tribunal constitucional. O bien los ciudadanos pueden recurrir a los tribunales ordinarios planteando una excepción de inconstitucionalidad en el momento en que el tribunal ante el cual se encuentran por otra cuestión, va a aplicarles la ley a propósito de esta última. La ley no se aplica entonces en este asunto, pero sigue teóricamente en vigor. Este sistema es el que se aplica en los Estados Unidos, donde el Tribunal Supremo asegura un control eficaz de la constitucionalidad de las leyes, por vía de apelación de las decisiones de los tribunales ordinarios". (DUVERGER, 1970; 242-243).-

2 "En la doctrina contemporánea del Derecho Constitucional se tiende a cambiar la denominación de los modelos, identificándolos como: a) modelo americano, al de la revisión judicial o control difuso; y b) modelo europeo, al control concentrado. Así, Francisco Rubio Llorente en su trabajo: Tendencias actuales de la Jurisdicción Constitucional en Europa, resume la clasificación de lo que él denomina como Jurisdicción Constitucional, en dos grandes modelos: el norteamericano, como forma del control difuso, en el que la decisión judicial no anula la ley ni la expulsa del ordenamiento, sino que simplemente la inaplica en el caso concreto; y el europeo, que concentra la jurisdicción constitucional en un tribunal único, que actúa como legislador negativo; en él la ley no es juzgada en relación con el caso concreto, sino a lo más con motivo de él, y en caso de ser considerada contraria a la Constitución es anulada; por lo tanto, expulsada del ordenamiento jurídico". (RIVERA, 2007; 32).
} 


\section{El sistema de control jurisdiccional de constitucionalidad}

Debemos comenzar precisando que en éste sistema, la labor del control de constitucionalidad está encomendada a un organismo jurisdiccional, es decir, un órgano que está dotado de jurisdicción y competencia para ejercer dicho control, a través de procedimientos extraordinarios y especiales previstos en la Ley.

Según la doctrina constitucional, el sistema de control jurisdiccional, admite a su vez dos modalidades, tomando en cuenta el órgano jurisdiccional que cumple la labor del control de la constitucionalidad, así como la vía a través de la cual se activa el control, y los efectos de la decisión que adopta el órgano encargado del control.

De ahí que, generalmente se identifican dos modelos: el modelo americano o difuso, y el modelo europeo o concentrado.

\section{El modelo americano o de la revisión judicial (judicial review of legislation) ${ }^{3}$}

Es conocido clásicamente como el modelo de control jurisdiccional difuso, y se caracteriza porque todos los jueces tienen la potestad y obligación legal de aplicar la Constitución con preferencia a las leyes, y éstas con preferencia a los decretos o resoluciones; de manera que, como dice Fernández Segado, todos los jueces están habilitados para inaplicar aquellas leyes que juzguen contrarias a la Constitución.

En otras palabras, y según el respetable criterio del maestro mexicano Dr. Héctor Fix-Zamudio (1924-2021), este sistema es calificado como "americano", no sólo por haberse establecido en sus lineamientos esenciales, en la Constitución Norteamericana de 1787 (con antecedentes en la legislación y en la jurisprudencia de las colonias inglesas en América), sino también por haber servido de paradigma a la abrumadora mayoría de los países americanos (de Argentina a Canadá).

En principio -agregaba Fix-Zamudio (†)- este sistema americano de la revisión judicial de la constitucionalidad de las leyes, se caracteriza en forma abstracta, como la facultad atribuida a todos los jueces para declarar en un proceso concreto, la inaplicabilidad de las disposiciones legales secundarias que sean contrarias a la Constitución y con efectos sólo para las partes que han intervenido en esa controversia. (FIX-ZAMUDIO, 1989; 451-467).

\footnotetext{
$3 \quad$ Según el criterio del profesor peruano Domingo García Belaunde: “El control constitucional de las leyes, lo que en la tradición norteamericana se llama judicial review, o sea, revisión judicial, aun cuando de su traducción nada pueda desprenderse (como sucede con la gran mayoría de los términos jurídicos ingleses), está pues, presente en las colonias, y da sustento a la lucha que mantienen con la Corona, y también existe en la práctica de algunas de ellas. Pero curiosamente, no es aceptada en la Convención de Filadelfia de 1787, que fue la que sancionó la Constitución que todavía los rige. Es decir, no empece que el control judicial fue un tema contemplado y discutido en las sesiones de Filadelfia, al final no fue aprobado por los convencionales. Por eso es que el planteo de Marshall, en su famosa sentencia de 1803 en el caso Marbury vs. Madison, no deja de sorprender, vistos los antecedentes, ya que tal tema fue dejado de lado por la constituyente, pero retomado hábilmente por Marshall, que de esa manera pretendió salir de un aprieto político en el que lo había colocado la nueva administración, a cargo del Presidente Thomas Jefferson". (GARCÍA, 2003; 28).
} 
Asimismo, Fix-Zamudio nos muestra una visión esquemática de este sistema americano, señalando que sus elementos esenciales consisten en la facultad otorgada al órgano judicial difuso (es decir, a todos los jueces sin importar su jerarquía), para resolver las cuestiones de constitucionalidad de las leyes, siempre que la cuestión respectiva sea planteada por las partes y aun de oficio por el juez que conozca del asunto, en una controversia concreta; "lo que de manera incorrecta se ha calificado como 'vía de excepción', pero que los procesalistas italianos han denominado con mejor técnica, como 'cuestión prejudicial', si se toma en cuenta que el problema de la inconstitucionalidad debe considerarse como un aspecto incidental (procesalmente hablando), de la controversia principal en la cual se plantea". En el mismo sentido, Mauro Cappelletti señalaba que: "en este sistema se atribuye a todos los órganos judiciales de un ordenamiento jurídico, que lo ejerciten incidentalmente, con ocasión de la decisión de una causa de su competencia".

Cabe señalar que este modelo de control de constitucionalidad, tiene sus antecedentes en la doctrina desarrollada por el Juez inglés Edward Coke al resolver el "Bonham's case", en el año 1610, en defensa del common law y de su tradicional supremacía frente a los posibles excesos o arbitrios de la Corona y el Parlamento 4; doctrina que tuvo marcada influencia en los Estados Unidos de Norteamérica, donde por la vía del Derecho Jurisprudencial, los jueces y tribunales asumieron la función de velar por la primacía de la Constitución, concretamente a partir de la célebre sentencia emitida por el juez John Marshall al resolver el caso "Marbury vs. Madison"5; de manera que los jueces y tribunales desarrollan la labor del control de constitucionalidad con la firme convicción de que velar por la Constitución es tanto como proteger la libertad misma, así como el sistema de valores sobre los que se asienta la convivencia social y, por lo mismo el gobierno de la colectividad, que en el marco de esa doctrina constituye un gobierno limitado por la Constitución (RIVERA, 2007; 37) ${ }^{6}$.

\footnotetext{
$4 \quad$ En 1610, en el cuarto argumento del Caso Bonham -que básicamente implicaba la formulación primigenia de la teoría constitucional de la judicial review-, Sir Edward Coke sostuvo: "Y aparece en nuestros Libros, que en muchos casos el Derecho común controla las leyes del Parlamento, y a veces debe declararlas nulas, pues cuando una ley del Parlamento es contraria al Derecho común y la razón, contradictoria o imposible de ser cumplida, el Derecho común debe tener autoridad sobre ella y declarar que tal ley es nula". Un estudio muy interesante acerca de la peculiar trayectoria pública de Sir Edward Coke (1552-1634), con una breve aproximación a su pensamiento jurídico, los hechos y argumentos en que se sustentaba la sentencia del Bonham's Case (1610), así como los precedentes jurisprudenciales en que Coke apoyó su dictum, pueden verse en el exhaustivo trabajo de (FERNÁNDEZ, 2013). Existe un estudio adicional sobre esta temática, que intenta mostrar cómo el Bonham's Case puede ser interpretado desde otra clave distinta a la tesis mayoritaria (que ve en esta decisión, uno de los más claros antecedentes de la creación posterior de la técnica de la judicial review por los jueces y tribunales norteamericanos); "de modo que, admitido que influyó en el proceso norteamericano de gestación del control de constitucionalidad de las leyes, podría considerarse, a la vez, que esto no tuvo necesariamente que ser así. En otras palabras, del Bonham's Case no se deriva por fuerza, la idea de que Coke creyera en la existencia de una norma superior (que más tarde y en otro lugar, se identificaría como 'constitucional') a partir de la cual sería posible (e incluso necesario) juzgar la validez de las leyes". (REY, 2008; 847-866)

$5 \quad$ El estudio de la evolución de los sistemas de control de constitucionalidad, está íntimamente ligado a la idea de la supremacía constitucional, que ciertamente nace en Inglaterra y se extiende hacia los Estados Unidos de Norteamérica, a través de dos casos de singular trascendencia: 1) el caso “Thomas Bonham” en Inglaterra, y 2) el caso “Marbury contra Madison" en EE.UU. Ambos constituyen los precedentes más claros en la evolución del control de constitucionalidad, y son explicados resumidamente por: (DURAN, 2003; 157-175). Un estudio que compila los principales antecedentes del control de constitucionalidad, desde el caso Thomas Bonham (en Inglaterra), en el cual el Presidente del Tribunal de Agravios Civiles, Sir Edward Coke, prescribió que toda ley contraria a la razón y a los principios de derecho común (Common Law) debía ser anulada e invalidada por el tribunal; hasta los más novedosos métodos para la protección de los derechos humanos basados en la figura sueca del Ombudsman, pasando por la célebre sentencia Marbury vs. Madison, proyectada por el Presidente de la Suprema Corte de Justicia de los Estados Unidos de América, John Marshall, que marcara el inicio de la Judicial Review; además del nacimiento a la vida jurídica de la Constitución yucateca de 1841 y, con ésta, del amparo, asi como los primeros juicios de garantías sustanciados en aquel país, hasta el surgimiento del amparo judicial; puede consultarse en la obra de: (GONZALEZ, 2003). Asimismo, un interesante ensayo que trata detalladamente acerca del juicio más importante en la historia de los Estados Unidos: el caso Marbury vs. Madison, en el cual el juez John Marshall que presidía la Suprema Corte de los Estados Unidos y los otros cinco jueces de esa Corte, decidieron que tenían el poder de revisar las leyes hechas por los representantes de la población y de los Estados en el Congreso de la Unión, y que tenían además el poder de nulificar dichas leyes si, en su opinión, eran contrarias a la Constitución; puede consultarse en el trabajo de: (VALDES, 2005; 313-345). Por otro lado, para comprender el sentido de la Sentencia Marbury Vs. Madison, teniendo presente el contexto histórico y político en que el fallo se produjo, así como los múltiples factores que condujeron a la trascendental decisión, recomiendo consultar también: (CARBONELL, 2006; 289-300).

$6 \quad$ Un estudio extenso y bastante detallado acerca de la Sentencia emitida en el caso Marbury vs. Madison, su enfoque sistemático, el iter argumental de la Sentencia, así como algunas precisiones importantes sobre la doctrina de la judicial review, su
} 
El razonamiento del juez norteamericano John Marshall 7, en la resolución de ese caso emblemático de control jurisdiccional difuso de constitucionalidad, constituye una aplicación práctica del principio de supremacía constitucional, cuando señala:

“... o bien la Constitución es una Ley suprema, que se encuentra por encima de todas las demás y no es modificable por medios ordinarios, o bien se encuentra al mismo nivel de los actos legislativos ordinarios y, como los demás actos, es alterable a gusto de la Legislatura. Si la primera parte de esta observación es verdadera, entonces un acto legislativo contrario a la Constitución no es Ley; si la última parte fuera cierta, entonces las Constituciones escritas serían tentativas absurdas de parte del pueblo para limitar un poder ilimitable por su propia naturaleza". (ASBUN, 2007; 87)

Por su parte, el reconocido jurista argentino Carlos Santiago Nino, ha intentado sistematizar algunas premisas y una conclusión, respecto a la estructura lógica del razonamiento del juez Marshall; $y$ describe dicho razonamiento de la siguiente forma:

Premisa 1. La obligación del poder judicial es aplicar la ley.

Premisa 2. Cuando existen dos leyes contradictorias, la aplicación de una de ellas excluye la aplicación de la otra.

Premisa 3. La Constitución es la ley suprema y define cuándo otras normas son ley.

Premisa 4. La supremacía de la Constitución implica que cuando está en conflicto con una norma sancionada por la Legislatura, esta última carece de validez.

Premisa 5. Si la premisa anterior no fuera verdadera, la Legislatura podría modificar la Constitución a través de una ley ordinaria y, de este modo, la Constitución no sería operativa para limitar a esa Legislatura.

fundamentación, puede verse en el trabajo publicado por el Catedrático de Derecho Constitucional, de la Facultad de Derecho de la Universidad Complutense de Madrid, (FERNÁNDEZ, 2011; 7-133). Por otro lado, un reciente trabajo de investigación sobre el tema, propone revisar ciertos mitos acerca del rol que habrían tenido tanto el Chief Justice John Marshall como su decisión en el fallo Marbury v. Madison en relación con el origen del control judicial de constitucionalidad (GARCÍA-MANSILLA, 2020; 9-89).

$7 \quad$ Para comprender adecuadamente la situación en que se encontraba el juez John Marshall, cuyo genio jurídico está fuera de toda discusión, acudimos al panorama detallado que describe García Belaunde en los siguientes términos: "hay que recordar que Marshall se encontraba arrinconado, que el caso lo demoró en resolver más de un año, y que al final, no le dio la razón ni al demandante ni al Gobierno, sino que se fue por la tangente, apelando al principio de la supremacía de la Constitución sobre la ley de la judicatura de 1789. Ahora bien, sentado el principio de que los jueces podían controlar la constitucionalidad de las leyes, llama la atención que nada hubiese pasado entonces, y que no hayan existido reacciones aparentes contra tal fallo. Pero cabe imaginar que algo tuvo que repercutir en los círculos gubernamentales, y lo más probable es que el gobierno no expresase públicamente su desagrado, ya que el fallo lo beneficiaba, motivo por el cual, el principio quedó así sentado, y en forma definitiva. Pero que tal sentencia provocó un verdadero terremoto en las altas esferas del gobierno, es algo que no puede descartarse, como lo comprueba la correspondencia de Jefferson, publicada con posterioridad (cf. Albert J. Beveridge, The life of John Marshall, Cherokee Pub. Co., Atlanta 1990, vol. III, pp. 141 ss.) Y eso explica por qué el Juez Marshall nunca más volvió a utilizar el control constitucional, así como jamás volvió a inaplicar una ley federal durante su larga carrera judicial, que duró hasta 1835. Esto es, desde 1803 en que se da el fallo Marbury vs. Madison hasta 1835, que es un lapso de 32 años, el Juez Marshall no volvió a invocar tal principio, sino que por el contrario, se dedicó a reafirmar el naciente derecho norteamericano y a ratificar las prerrogativas del Congreso (si bien lo hizo muy sutilmente). Aún más, el control judicial sólo es vuelto a utilizar en 1857, en el caso Dred Scott vs. Sandford, bajo otra Corte y con otro Presidente, el Juez Taney, y sólo empieza a tener cierta importancia a fines del siglo pasado. Y tan sólo durante la llamada revolución constitucional en la época de Roosevelt, ya en pleno siglo veinte, es que el principio se afirma, y en puridad de verdad, el caso Marbury vs. Madison se vuelve un auténtico leading case (es decir, caso líder, que orienta y sirve de fundamento a lo que viene después)". (GARCíA, 2003; 29). Un resumen de los argumentos judiciales más relevantes, que fueron expuestos en los casos Marbury vs. Madison (1803) y Dred Scott vs. Sandford (1857), pueden consultarse en: (MORRIS, 1962; 134, 184). 
Premisa 6. La Legislatura está limitada por la Constitución.

Premisa 7. Si una norma no es una ley válida, ésta carece de fuerza obligatoria.

Conclusión: Si una norma sancionada por la Legislatura es contraria a la Constitución, esa norma no debe ser aplicada por el Poder Judicial.(NINO, 2003; 261-262)

De lo anterior se infiere, que si una Ley es contraria a la Constitución, no debe ser aplicada por el Poder Judicial, es decir, que los jueces deben abstenerse de aplicar las normas que sean contrarias al texto constitucional, estableciéndose así el control judicial de constitucionalidad.

En ese contexto, cabe señalar que el modelo de control difuso de constitucionalidad tiene principalmente las características que se describen a continuación ${ }^{8}$ :

$\checkmark$ Todos los órganos judiciales ordinarios, jueces y tribunales, pueden pronunciarse sobre la constitucionalidad de las leyes cuando conocen y resuelven las controversias suscitadas ante ellos, en los casos sometidos a su competencia.

$\checkmark$ La ley sospechosa de inconstitucionalidad no es susceptible de impugnación directa, pues la presunta inconstitucionalidad sólo puede hacerse valer como cuestión incidental, de cuya resolución depende la decisión que, sobre el caso principal, ha de adoptar el juez competente.

$\checkmark$ Están legitimadas para solicitar o promover el control, únicamente las partes en litigio, es decir las partes del proceso en el cual se debe aplicar la norma supuestamente inconstitucional.

$\checkmark$ En este sistema, el Juez no anula la ley, sino que declara una nulidad preexistente, inaplicando la disposición legal al caso que está conociendo, de manera que los efectos de su declaración están limitados al caso concreto. (RIVERA, 2007; 35)

En el caso de Bolivia, y atendiendo a la evolución que tuvo el sistema de control constitucional establecido por nuestra misma Ley Fundamental, la Corte Suprema de Justicia fue considerada por largo tiempo como la "guardiana de la Constitución", dado que estaba especialmente designada a asegurar la supremacía de la misma frente a cualquier Ley, Decreto, Ordenanza o Resolución que estuviera en oposición a sus preceptos.

En efecto, la atribución 5ta., del artículo 127 en que la Constitución Política de 1967 establecía las atribuciones que tenía la Corte Suprema de Justicia, además de las señaladas por ley, indicaba: “(...) Conocer en única instancia de los asuntos de puro derecho cuya decisión depende

$8 \quad$ Ciertamente, de acuerdo a sus rasgos más generales, el régimen norteamericano realiza un control de constitucionalidad difuso, también llamado desconcentrado, lo que implica que cualquier juez del Poder Judicial, de cualquier fuero (civil, comercial, penal, laboral, etc.) como regla, puede declarar en un proceso la inconstitucionalidad de las normas. "A su vez, las sentencias se efectivizan solamente inter partes, y para el caso concreto: la ley definida por un juez como inconstitucional, sigue vigente (solamente se la inaplica en el caso judicial específico donde se la reputó inconstitucional). No obstante, por el principio del stare decisis, las sentencias de la Corte Suprema de los Estados Unidos de América tienen un valor especial, y deben ser seguidas por los tribunales inferiores, con lo que -en particular en materia de declaración de inconstitucionalidad- hay un cierto efecto erga omnes de tales veredictos de inconstitucionalidad". (SAGÜÉS, 2004; 28-29). 
de la constitucionalidad de las leyes y cualquier género de resoluciones" 9 . Y fue precisamente con base en ésta disposición que la entonces Corte Suprema de Justicia en Bolivia, al igual que en casi todos los Estados latinoamericanos, asumió el elevado rol de ser "guardiana de la Constitución" y por consiguiente, el de ser contralor sobre la constitucionalidad de las leyes.

Como bien se conoce, de acuerdo al artículo 228 de aquella Constitución abrogada, los tribunales, jueces y autoridades tenían el deber de aplicarla con preferencia a las leyes, y a éstas con preferencia a cualesquiera otras resoluciones, con el advertido de que quedaban abrogadas las leyes y disposiciones que se opusieran a lo dispuesto por la Constitución, por lo cual, las leyes o los decretos contrarios a la Ley Fundamental, que eventualmente pudieran vulnerar derechos civiles, políticos o institucionales por ella garantizados, eran considerados nulos de hecho, sin embargo dicha nulidad no podía ser declarada (de oficio) por la Corte Suprema de Justicia, si no era a instancia de la persona o entidad afectada (o perjudicada), siendo que la sentencia no tenía mayor validez si no exclusivamente para el caso concreto.

De ahí que, la declaración de inconstitucionalidad obtenida válidamente mediante el procedimiento establecido para los "juicios de puro derecho", tenía como efecto inmediato la no aplicación o ejecución de la ley, decreto o resolución, en el caso demandado exclusivamente, ya que el Poder Judicial no podía ni debía, en ninguna manera, ir más allá de la declaración de inejecución en cada caso particular, dado que de acuerdo a la configuración de sus atribuciones, carecía de potestad para abrogar o derogar (dejar sin efecto) las leyes o los actos jurídicos inconstitucionales, porque ello hubiera significado el quebrantamiento del principio básico del gobierno republicano democrático, fundado en la "independencia y coordinación de los poderes”, conforme establecía el artículo $2^{\circ}$ de la entonces vigente Constitución de 1967 (DAZA, 1974; 167).

Sin embargo, como se verá enseguida, durante el tiempo de su vigencia, este modelo no cumplió las expectativas de lograr un control efectivo de la constitucionalidad.

\section{El control jurisdiccional difuso de constitucionalidad y su vigencia en Bolivia}

Resulta importante reseñar, que en la reforma constitucional del año 1861, paralelamente a la creación del Consejo de Estado, se adoptó el modelo de control de constitucionalidad conocido como control jurisdiccional difuso o modelo americano; toda vez que la Constitución reformada consagró, por una parte, el principio de la supremacía constitucional cuando en su artículo 86 estableció textualmente lo siguiente: "Las autoridades y tribunales aplicarán esta Constitución

$9 \quad$ "La Constitución de 1861, en el inciso $2^{\circ}$ de su artículo 65, introdujo por primera vez este recurso de puro derecho destinado a proteger la superlegalidad y primacía de la Constitución, cuyas normas no pueden ser contradichas por las leyes secundarias en su más amplia acepción, constituyendo además una de las mayores garantías para asegurar los derechos consignados en la Ley Fundamental, contra los abusos del Poder. La Constitución de 1861 al establecer las atribuciones de la Corte Suprema, expresaba en su mencionado inciso $2^{\circ}$ : Conocer de los negocios de puro derecho, cuya decisión depende de la constitucionalidad o inconstitucionalidad de las leyes. Este precepto se mantuvo con los mismos términos en el inciso $2^{\circ}$ del artículo 79 de la Constitución de 1868 y en la de 1871 . A partir de la Constitución de 1878, el precepto se lo amplió en los términos en que existen actualmente". (DAZA, 1974; 165). Algunas premisas de la doctrina judicial boliviana, en cuanto a los procesos de inconstitucionalidad o de inaplicabilidad, pueden encontrarse en los escritos y discursos de ilustres jurisconsultos bolivianos, tales como: Pantaleón Dalence (1887), Saturnino Sanjinés (1892), Belisario Boeto (1898), y Luis Paz (1921); todos ellos citados por: (VIRREIRA, 1977; 88-92). Dichos criterios fueron posteriormente sintetizados en el Auto Supremo N 2 de fecha 13 de febrero de 1990. (CORTE SUPREMA DE JUSTICIA, 1991; 756). 
con preferencia a las leyes, y éstas con preferencia a cualesquiera otras resoluciones" y, al mismo tiempo, encomendó la labor de control de constitucionalidad, por la vía de acción concreta, al Tribunal Supremo de Justicia, cuando en su artículo 65 dispuso que: "son atribuciones de la Corte de Casación (Tribunal Supremo de Justicia), además de las que señalan las leyes: $2^{\circ}$ Conocer de los negocios de puro derecho, cuya decisión depende de la constitucionalidad o inconstitucionalidad de las leyes".(TRIGO, 2003; 358).

Posteriormente, en la reforma constitucional realizada el año 1868 se suprimió el Consejo de Estado, manteniéndose invariable la atribución de la "Corte de Casación" (ahora denominado Tribunal Supremo de Justicia), de conocer de los negocios de puro derecho, cuya decisión depende de la constitucionalidad de las leyes; empero, en la reforma del año 1871 se restableció nuevamente con modificaciones en su composición y atribuciones, conforme a las cuales, se le otorgó la atribución de ejercer el control de constitucionalidad en el orden normativo preventivo y correctivo.

Entonces, sobre la base de la norma constitucional incorporada en 1861, y que se mantuvo inalterable en 1868, se organizó el control jurisdiccional difuso de constitucionalidad ejercido por todos los jueces y tribunales del país, que al resolver un caso concreto, tenían la atribución y obligación de inaplicar una disposición claramente incompatible con las normas de la Constitución; asimismo, el control era ejercido por la Corte Suprema de Justicia, la que tenía la facultad y atribución de conocer y tramitar el recurso de inaplicabilidad por inconstitucionalidad de una disposición legal, cuya decisión sólo tenía un efecto inter partes, es decir, para el caso concreto ${ }^{10}$.

Resumiendo -y de acuerdo a lo analizado por Rivera Santivañez-, podemos decir que el modelo de control jurisdiccional difuso de constitucionalidad vigente entre los años 1861 a 1938, tuvo las siguientes características:

a) En lo que se refiere a los alcances del control, abarcaba a dos ámbitos: i) el normativo, es decir, el control sobre las leyes, decretos y cualquier género de resoluciones de carácter normativo general, labor ejercida a través de la acción de inaplicabilidad por inconstitucionalidad; $y$, ii) el competencial, es decir, el control sobre el ejercicio de las atribuciones y competencias otorgadas por la Constitución y las Leyes a las autoridades públicas, labor desempeñada a través del recurso directo de nulidad. Esto significa que estuvo excluido del sistema el control tutelar de los derechos fundamentales.

\footnotetext{
$10 \quad$ "El nuevo Código de Procedimiento Civil, dice pues, que el proceso de inconstitucionalidad procede en todos los casos en que una persona individual o colectiva (natural o jurídica) 'se creyere agraviada por los efectos de una ley, decreto o cualquier género de resolución', pudiendo interponer la respectiva demanda ante el Supremo Tribunal pidiendo 'se declare la inaplicabilidad' de la ley, del decreto o de la resolución, en todo o en parte, en el caso concreto en que el demandante se cree agraviado. Se pide la declaración de 'inaplicabilidad' de la ley, decreto o resolución, por 'inconstitucional', porque el Poder Judicial no puede declarar llanamente la inconstitucionalidad, ya que no es 'censor directo de los Poderes Legislativo y Ejecutivo'. Y, esa declaración deberá recaer sobre el punto concreto demandado (...)" (VIRREIRA, 1977; 93).
} 
b) Respecto a los órganos encargados de ejercer el control normativo de constitucionalidad, el modelo era mixto; pues de un lado, tenía los elementos del control difuso en la medida en que todos los jueces y tribunales judiciales, al resolver un caso concreto, podían inaplicar la disposición legal que consideren inconstitucional; y, de otro, la Corte Suprema de Justicia ejercía un control concentrado por la vía de la acción de inaplicabilidad por inconstitucionalidad.

c) Con relación a los efectos de las decisiones emitidas en el control normativo, éstas tenían efecto inter partes, dado que no anulaban la disposición legal declarada inconstitucional, sino simplemente declaraban la nulidad preexistente disponiendo su inaplicación al caso concreto.

En cambio, el modelo de control que estuvo vigente entre los años 1938 a 1999, tuvo la variante de haberse incluido el control tutelar de los derechos fundamentales, inicialmente a través del Recurso de Hábeas Corpus, aprobado mediante el Referéndum Popular de 1931 e incorporado a la Constitución en la Convención Nacional Constituyente de 1938; posteriormente con la adopción del Recurso de Amparo en la Asamblea Nacional Constituyente de 1967, y la promulgación del Código de Procedimiento Civil (1975) que introdujo el Recurso contra Resoluciones Legislativas y el Recurso contra impuestos ilegales. Por lo demás, se mantuvieron las características ya descritas anteriormente (RIVERA, 2007; 55).

Sin embargo, y de acuerdo al criterio del ex Magistrado del Tribunal Constitucional de Bolivia, Dr. José Antonio Rivera Santivañez, ese modelo de control "difuso" de constitucionalidad no rindió los frutos esperados, debido a diversas razones, entre las que se pueden señalar las siguientes:

i) la no vigencia permanente del régimen democrático de gobierno y del Estado de Derecho, que a lo largo de la historia republicana tuvo una presencia fugaz, debido a las permanentes interrupciones mediante los golpes de Estado que instauraron regímenes de hecho o De Facto;

ii) la falta de una doctrina constitucional boliviana sólida y carencia de una cultura constitucional; pues habrá de recordar que por la falta de una vigencia material de la Constitución el Derecho Constitucional fue objeto de un estudio enciclopédico más que práctico y concreto, además que el sistema constitucional boliviano se configuró sobre la base del constitucionalismo clásico, por lo tanto, sobre la base del principio de legalidad y no tanto del principio de supremacía constitucional, lo que dio lugar a que se catalogara la Constitución como una mera carta política y no una norma jurídica, cuando menos eso sucedió en el Siglo XX y las primeras ocho décadas del Siglo XX;

iii) la incompleta positivación de los derechos humanos y la falta de judicialización de los mismos, pues habrá de recordar que en esa materia la Constitución no fue generosa, ya que recién en 1931 se introdujo el hábeas corpus como garantía para el derecho a la libertad física, y el amparo constitucional en 1967; ello incidió significativamente en la poca ineficacia del sistema en el control tutelar de constitucionalidad; $y$, 
iv) extremada concentración de funciones en la Corte Suprema de Justicia, como la función jurisdiccional ordinaria y contenciosa, la jurisdicción constitucional y la labor administrativa y disciplinaria, que incidió en la generación de la retardación de justicia y que el control de constitucionalidad no tuviese la eficacia esperada (RIVERA, 2008; 46).

De ahí que -en criterio acertado de Rivera Santivañez, y al cual nos adscribimos-, haciendo una evaluación objetiva del control de constitucionalidad en la etapa anterior a la creación del Tribunal Constitucional, se puede concluir que no fue eficiente ni logró los resultados esperados, pues no existió un desarrollo doctrinal ni jurisprudencial sólido, sino que por el contrario, se caracterizó por la excesiva retardación de justicia (RIVERA, 2007).

\section{CONCLUSIONES}

Lo expuesto, es cuanto se puede analizar en ocasión de un aniversario más del nacimiento del sistema de control jurisdiccional difuso de constitucionalidad, que se ha caracterizado principalmente porque todos los jueces tienen la potestad y obligación legal de aplicar la Constitución con preferencia a las leyes, y éstas con preferencia a los decretos o resoluciones; de manera que, todos los jueces están habilitados para inaplicar aquellas leyes que juzguen contrarias a la Constitución, no obstante las señales de su vigencia no muy efectiva en Bolivia.

Sin embargo, cabe destacar sobre todo la enorme influencia que ha tenido en la enseñanza del Derecho Constitucional, dado que su utilidad radica en que muestra claramente la evolución que han tenido los sistemas de control de constitucionalidad, como mecanismos idóneos para lograr la efectividad de los mandatos establecidos por la Constitución; más aún si se considera que en el caso de Bolivia, en un primer momento de su vida republicana (1826 - 1861), bajo la influencia del liberalismo francés, configuró un modelo político de control de constitucionalidad a través de un Consejo de Estado; en una segunda etapa (1861 - 1994) adoptó este modelo americano, es decir, el sistema jurisdiccional difuso de control de constitucionalidad a través de la Corte Suprema de Justicia; en la tercera etapa (1994 - 2009) adoptó el modelo europeo, es decir, el sistema jurisdiccional concentrado de control de constitucionalidad con la atribución exclusiva del control a un órgano especializado proveniente del modelo europeo, que fue denominado Tribunal Constitucional; y finalmente, en la cuarta etapa (2009 hacia adelante), se ha configurado constitucionalmente un sistema predominantemente concentrado y plural de constitucionalidad en Bolivia, según el entendimiento desarrollado por la jurisprudencia del Tribunal Constitucional Plurinacional, a partir de la interpretación de las normas establecidas por la Constitución aprobada el año 2009. 


\section{REFERENCIAS}

ASBUN, Jorge (2007). Derecho Constitucional General. Conceptos Jurídicos Básicos. Quinta Edición. Cochabamba, Bolivia: Grupo Editorial Kipus.

CARBONELL, Miguel (2006). Marbury versus Madison: en los orígenes de la supremacía constitucional y el control de constitucionalidad. En: Revista Iberoamericana de Derecho Procesal Constitucional. Proceso y Constitución. $N^{\circ}$ 5. México: Editorial Porrúa, Enero-Junio. Págs. 289-300. Una versión digital del texto, se encuentra disponible en Scribd: http://es.scribd.com/doc/252004352

CORTE SUPREMA DE JUSTICIA DE LA NACIÓN (1991). Labores Judiciales 1990. Sucre, Bolivia: Editorial Judicial. Pág. 756.

DAZA ONDARZA, Ernesto (1974). Doce Temas de Derecho Constitucional. Cochabamba, Bolivia: Editorial Universitaria UMSS.

DURAN RIBERA, Willman R. (2003) El sistema de control de constitucionalidad vigente en Bolivia. En: TRIBUNAL CONSTITUCIONAL DE BOLIVIA. La Justicia Constitucional en Bolivia 1998 - 2003. Sucre, Bolivia: Grupo Editorial Kipus.

DUVERGER, Maurice (1970). Instituciones Políticas y Derecho Constitucional. Quinta edición española, totalmente refundida, dirigida por Jorge Solé-Tura. Barcelona, España: Ediciones Ariel.

FERNÁNDEZ SEGADO, Francisco (2011). La sentencia Marbury v. Madison. Revista De Las Cortes Generales, (83), 7-133. Disponible en: https://doi.org/10.33426/rcg/2011/83/477

FERNÁNDEZ SEGADO, Francisco (2013). Sir Edward Coke, el Bonham's Case y la Judicial Review. Ponencia presentada al XI Congreso Iberoamericano de Derecho Constitucional. Tucumán - Argentina (17 al 19 de septiembre de 2013).

FIX-ZAMUDIO, Héctor (1989). La Justicia Constitucional en América Latina. En: VV.AA. El Constitucionalismo en las postrimerías del siglo XX. Tomo IV. Constitucionalismo. Colaboraciones extranjeras y nacionales. México: Instituto de Investigaciones Jurídicas de la Universidad Nacional Autónoma de México. Disponible en: http://bibliohistorico. juridicas.unam.mx/libros/libro.htm?l=703
GARCÍA BELAUNDE, Domingo (2003). De la JurisdicciónConstitucionalalDerechoProcesal Constitucional. Cuarta Edición revisada, corregida y aumentada. Edición al cuidado y prólogo de José F. Palomino Manchego. Lima, Perú: Instituto Iberoamericano de Derecho Constitucional (Sección Peruana). Disponible virtualmente en: http://www.garciabelaunde. com/Biblioteca/delajurisdiccion.pdf

MORRIS, Richard B. (1962) Documentos fundamentales de la Historia de los Estados Unidos de América. México: Editorial Libreros Mexicanos Unidos S.A.

GARCÍA-MANSILLA, Manuel José. (2020). Marbury v. Madison y los mitos acerca del control judicial de Constitucionalidad. Revista Jurídica Austral, (1). Disponible en: https://doi. org/10.26422/RJA.2020.0101.gar

GONZÁLEZ OROPEZA, Manuel (2003). Los orígenes del Control Jurisdiccional de la Constitución y de los Derechos Humanos. México D.F.: Comisión Nacional de los Derechos Humanos. Disponible en: http://bit.ly/2bpeQis

NINO, Carlos S. (2003) La Constitución de la democracia deliberativa. Primera reimpresión. Barcelona, España: Editorial Gedisa S.A.

REY MARTÍNEZ, Fernando (2008). Una relectura del Dr. Bonham's Case y de la aportación de Sir Edward Coke a la creación de la judicial review. En: FERRER MAC-GREGOR, Eduardo y ZALDÍVAR LELO DE LARREA, Arturo (Coords.). La Ciencia del Derecho Procesal Constitucional. Tomo I. Teoría General del Derecho Procesal Constitucional. México: Instituto de Investigaciones Jurídicas de la Universidad Nacional Autónoma de México - Instituto Mexicano de Derecho Procesal Constitucional. Págs. 847-866. Disponible en: http://bit.ly/2bs17HV

RIVERA SANTIVAÑEZ, José Antonio (2007). El Tribunal Constitucional defensor de la Constitución. Reflexiones sobre la necesidad de su consolidación y fortalecimiento institucional. Sucre, Bolivia: GTZ - PADEP, Unión Europea, AECI. 
RIVERA SANTIVAÑEZ, José Antonio (2008). El Tribunal Constitucional: una década transitando un sendero con obstáculos. En: Revista Opiniones y Análisis $\mathrm{N}^{\circ}$ 90. Los árbitros de la vida institucional boliviana. La Paz, Bolivia: Fundemos.

RIVERA SANTIVAÑEZ, José Antonio (2007). Temas de Derecho Procesal Constitucional. Cochabamba, Bolivia: Editorial Kipus.

SAGÜÉS, Néstor Pedro (2004). El sistema de derechos, magistratura y procesos constitucionales en América Latina. Biblioteca Porrúa de Derecho Procesal Constitucional $N^{\circ} 1$. México, D.F.: Editorial Porrúa.

TRIGO, Ciro Félix (2003). Las Constituciones de Bolivia. Prólogo de Manuel Fraga Iribarne. Adiciones y actualizaciones (1961 - 2002), Dr. Jorge Antonio Asbun Rojas. Segunda Edición.
La Paz, Bolivia: Fondo Editorial de la Biblioteca y Archivo Histórico del Honorable Congreso Nacional.

VALDES S., Clemente (2005). Marbury vs. Madison. Un ensayo sobre el origen del poder de los jueces en los Estados Unidos. En: Revista Iberoamericana de Derecho Procesal Constitucional. Proceso y Constitución. $\mathrm{N}^{\circ}$ 4. México: Editorial Porrúa, Julio-Diciembre. Págs. 313-345.

VIRREIRA FLOR, Rodolfo (1977). De los Procesos y Recursos previstos en la Constitución Política del Estado. En: CORTE SUPREMA DE JUSTICIA DE LA NACIÓN. 5 Estudios Jurídicos (sobre temas de los nuevos Códigos bolivianos, Civil y de Procedimiento Civil). Volumen I. Sucre, Bolivia: Biblioteca Jurídica. Págs. 88-92. 